Journal of Accident and Emergency Medicine 1995 12, 173-176

\title{
A comparison of symptoms experienced following minor head injury and acute neck strain (whiplash injury)
}

\author{
K. BARRETT ${ }^{1}$, N. BUXTON ${ }^{2}$, A.D. REDMOND ${ }^{2}$, J.M. JONES ${ }^{3}$, \\ A. BOUGHEY ${ }^{4}$, A.B. WARD ${ }^{4}$
}

'Department of Psychiatry, School of Postgraduate Medicine, Stoke-on-Trent, 'Department of Emergency Medicine, Trauma Centre, North Staffordshire Hospital, Stoke-on-Trent, ${ }^{3}$ Department of Mathematics, Keele University, Staffordshire and ${ }^{4}$ Department of Rehabilitation Medicine, Haywood Hospital, Stoke-on-Trent

\section{SUMMARY}

The symptoms reported by patients who have experienced minor head or minor neck injury are compared. Symptoms were identified using a questionnaire-based out-patients interview.

Rank order correlation analyses were carried out on data obtained at 2 and 6-12 weeks post-injury. Data on 24 head-injured and 29 neck-injured patients are presented. There was a significant rank order correlation at both assessments but neck injured patients reported more phobia (fear of travelling in car) and depression, and head-injured more dizziness. It is likely that neck-injury contributes to the symptomatology experienced after minor head injury, and vice-versa.

Keywords: acute neck strain, head injury, whiplash

\section{INTRODUCTION}

Head injuries are classed as 'minor' if they result in only a very brief period of unconsciousness or confusion. However, a minority of such patients suffer disabling symptoms for many months and even years. ${ }^{1,2}$ In an earlier study ${ }^{3}$ we examined symptoms following minor head-injury and compared patients who were admitted to hospital for observation with patients who were not admitted, using a questionnaire covering post-concussive and related symptoms. The most common and persistent symptom in patients who were not admitted (few of whom had been unconscious) was neck-ache. This led us to speculate that flexion/extension injury of the neck might contribute to the sequelae of minor head injury and led us to examine the frequency of the 'postconcussive' symptoms in a group of patients with acute neck strain (whiplash injury). This paper describes the result of this study.

\section{METHODS}

Two subject groups were compared. The head- injured group included patients admitted to hospital for overnight observation following minor head injury. All had experienced a period of unconsciousness of less than $6 \mathrm{~h}$. Forty-eight patients admitted consecutively and aged over 16 years were given out-patient appointments for 2 weeks after injury. Those who attended were interviewed and given a follow-up appointment at 12 weeks after their injury.

The neck-injured group included 46 patients referred consecutively and aged over 16 years. Patients were followed up in an orthopaedic soft tissue clinic 2 weeks after attendance at the accident and emergency (A\&E) department following whiplash (flexion/extension) injury of the neck. None had lost consciousness as a result of their injury and radiographs of cervical spine revealed no abnormality. They were given a further appointment 6-12 weeks (mode $=8$ weeks) after injury.

In both groups the same questionnaire-based interview was conducted. This includes questions on demographic features, history of injury and return to work/leisure pursuits. There are direct questions on 30 symptoms. $^{3}$ In the head-injured group the interviews were conducted by a senior nurse of ward manager grade and in the neck-injured group a surgical senior house officer. All interviews took place in a hospital out-patient department. Data presented in the next section are from the patients in both groups who attended the first and second assessment.

\section{RESULTS}

The head-injured group comprised 15 males and nine females with an age range of 16 to 88 and a median age of 32 years. The neck-injured group comprised 
K. Barrett et al. 13 males and 16 females with an. age range of 17-73 years, and a median age of 31 years. These age and sex differences were found not to be statistically significant (Age: Mann Whitney $U$-test; $P=0.98$. Sex; $P=0.31$ ).
In the head-injured group, 24 patients attended the clinic at 2 and 12 weeks. In the neck-injured group 29 patients attended at 2 and $6-12$ weeks. In $100 \%$ of the neck-injured and in $37 \%$ of the head-injured patients the cause of the injury was a road traffic acci-

\begin{tabular}{|c|c|c|c|}
\hline First assessment & $(\%)$ & Second assessment & $(\%)$ \\
\hline \multicolumn{4}{|l|}{ Head injured } \\
\hline Symptom & & Symptom & \\
\hline Reduced vitality & 58.3 & Reduced vitality & 29.2 \\
\hline Irritability & 58.3 & Headache & 20.8 \\
\hline Headache & 45.8 & Irritability & 20.8 \\
\hline Dizziness & 45.8 & Anxiety & 20.8 \\
\hline Neck-ache & 41.7 & Impaired concentration & 16.7 \\
\hline Impaired concentration & 37.5 & Impaired memory & 16.7 \\
\hline Impaired sleep & 37.5 & Neck-ache & 16.7 \\
\hline Noise intolerance & 33.3 & Depression & 12.5 \\
\hline Reduced appetite & 29.2 & Dizziness & 12.5 \\
\hline Reduced interest & 29.2 & Aggression & 8.3 \\
\hline Anxiety & 29.2 & Reduced interest & 8.3 \\
\hline Aggression & 25.0 & Impaired sleep & 8.3 \\
\hline Depression & 20.8 & Light intolerance & 4.2 \\
\hline Impaired memory & 16.7 & Blurred vision & 4.2 \\
\hline Clumsiness & 16.7 & Numbness & 4.2 \\
\hline Weakness & 16.7 & Paraesthesia & 4.2 \\
\hline Paraesthesia & 16.7 & Weakness & 4.2 \\
\hline \multirow[t]{2}{*}{ Light intolerance } & 12.5 & Clumsiness & 4.2 \\
\hline & & Difficulty expressing & 4.2 \\
\hline
\end{tabular}

Table 1. Rank order of symptoms

\section{Neck injured}

Symptom

Neck-ache
Reduced vitality
Headache
Impaired sleep
Depression
Irritability
Phobia
Weakness
Paraesthesia
Anxiety
Breathlessness
Aggression
Numbness
Feelings of unreality
Impaired concentration
Impaired memory
Difficulty expressing
Dizziness

100.0

79.3

72.4

58.6

58.6

51.7

44.8

41.4

41.4

37.9

37.9

34.5

31.0

31.0

27.6

24.1

24.1

20.7
Symptom

$\begin{array}{ll}\text { Headache } & 51.7 \\ \text { Depression } & 31.0 \\ \text { Reduced vitality } & 27.6 \\ \text { Impaired sleep } & 27.6 \\ \text { Phobia } & 27.6 \\ \text { Anxiety } & 24.1 \\ \text { Aggression } & 24.1 \\ \text { Paraesthesia } & 24.1 \\ \text { Impaired memory } & 20.7 \\ \text { Irritability } & 20.7 \\ \text { Clumsiness } & 17.4 \\ \text { Difficulty expressing } & 17.4 \\ \text { Breathlessness } & 17.4 \\ \text { Numbness } & 13.8 \\ \text { Weakness } & 10.3 \\ \text { Feelings of unreality } & 10.3 \\ \text { Reduced vitality } & 10.3 \\ \text { Dizziness } & 10.3\end{array}$


Symptoms of minor head and neck injury dent. Of the other head injured patients, industrial and domestic injuries each accounted for $21 \%$, assaults for $8 \%$, sports for $8 \%$, and other causes for $5 \%$.

The rank order of the 19 symptoms most commonly reported in the two groups is presented in Table I, together with the results of Spearman's rank order correlation based on an analysis of all 30 symptoms. There was a significant correlation between the groups at both assessment points $(r=0.46, P=0.012$ at 2 weeks, $r=0.54, P=0.0045$ at $6-12$ weeks). The total number of symptoms reported by individuals in the two groups are presented in Table 2.

\section{DISCUSSION}

Our earlier paper suggested an overlap between post-concussive and post-whiplash syndromes. ${ }^{3}$ In the present paper we compare the relative frequency of the same set of symptoms in the two groups and reveal a significant correlation, although there are some notable differences in the frequency of particular symptoms. Neck-ache, reduced vitality, headache, irritability and impaired sleep were among the most frequently reported symptoms in both groups. Dizziness was more common in the head-injured $(45.8 \%)$ than in the neck-injured $(20.7 \%)$. Given that all the head-injured patients had been rendered unconscious by their injury this would support the theory of a brain stem aetiology for the dizziness in this group. Depression was common in the neck-injured (58.6 as compared with $20.8 \%$ ). New fears/phobias were reported by $44.8 \%$ of the neck-injured but none of the head-injured reported such fears. In all cases this was a fear of driving or travelling in a car. A total of $27.6 \%$ of patients reported this at the second

Table 2. Number of symptoms reported

\begin{tabular}{lllll}
\hline \multirow{2}{*}{ Number of symptoms } & \multicolumn{2}{c}{ Head-injured } & \multicolumn{2}{c}{ Neck-injured } \\
& 1st & 2nd & 1st & 2nd \\
\hline & & & & \\
0 & 4 & 12 & 0 & 2 \\
1 & 3 & 3 & 0 & 2 \\
2 & 0 & 2 & 1 & 4 \\
3 & 2 & 1 & 1 & 4 \\
4 & 0 & 2 & 2 & 5 \\
5 & 3 & 1 & 3 & 4 \\
6 & 1 & 0 & 1 & 1 \\
7 & 3 & 0 & 1 & 1 \\
8 & 1 & 1 & 0 & 4 \\
9 & 0 & 1 & 5 & 0 \\
10 & 0 & 0 & 0 & 1 \\
$>10$ & 7 & 2 & 11 & 3 \\
Range: & $0-16$ & $0-14$ & $2-20$ & $0-19$ \\
\hline
\end{tabular}

assessment, but in only one was this considered not to be improving.

The frequency and rank order of symptoms reported here in the neck-injured group is similar to that reported by Radanov et al. ${ }^{4}$ Radanov's group assessed 78 whiplash patients 1 week and 6 months after injury and reported the frequency of 15 symptoms. In our group persisting symptoms were still present in 27 patients (93\%) at the second assessment (on average 8 weeks after injury). At 6 months Radanov et al. found that 21 of 78 patients (30\%) continued to experience symptoms. ${ }^{4}$ Our results are also similar to those of Ettlin et al. ${ }^{5}$ who carried out a comprehensive assessment on 21 whiplash injury patients with follow-up at 3 days, 3 months and 1 year. However, their patients reported more cognitive symptoms than Radanov et al. or our group.

The pathological process initiated by injury that leads to early and persisting symptoms is not known but the studies cited above suggest a multi-factorial aetiology. Radanov et al. ${ }^{4}$ found that patients with persisting symptoms reported more severe pain on initial presentation and animal studies have revealed that extensive soft tissue damage can occur after seemingly minor neck injury. ${ }^{6,7}$ However, Radanov's group also found more recent adverse life stresses in the persisting symptom group. Based on the results of the present study we would suggest that minor head and neck injuries are part of a continuum: it is almost impossible to get one without some degree of the other. Hence the term 'minor head and neck injury' best describes both and the two syndromes could be investigated together.

\section{ACKNOWLEDGEMENTS}

The collection of the head injury data was supported by a grant from the Nuffield Provincial Hospitals Trust.

\section{REFERENCES}

1. Cartiledge N.E.F.\& Shaw D.A. (1981) The Postconcussional Syndrome in Head Injury pp.145-154. W.B. Saunders London.

2. Binder L.M. (1986) Persisting symptoms after mild head injury: a review of post-concussive syndrome. Journal of Clinical and Experimental Neuropsychology 8, 323346.

3. Barrett K., Ward A.B., Boughey A., Jones M. \& Mychalkiw W. (1994) Sequelae of minor head injury: The natural history of post-concussive symptoms and its 
relationship to loss of consciousness and follow-up. Journal of Accident and Emergency Medicine 11, 79-84.

4. Radanov B.P., Di Stefano G., Schnidrig A. \& Ballinari P. (1991) Role of psychosocial stress in recovery from common whiplash. Lancet 338, 712-715.

5. Ettlin T.M., Kischka U., Reichmann S., Radii E.W., Heim S., Wengen D., Benson F. (1992) Cerebral symptoms after whiplash injury of the neck: a prospective clinical and neuropsychological study of whiplash injury.
Journal of Neurology Neurosurgery and Psychiatry $\mathbf{5 5}$, 943-948.

6. Macnab I. (1964) Acceleration injuries of the cervical spine. Journal of Bone and Joint Surgery 46A, 1797-99.

7. Wickstrom J. Martinez J. \& Rodriguez R. (1967) Cervical sprain syndrome: experimental acceleration injuries of the head and neck. Proceedings of symposium April, 1967, University of Michigan, pp. 182-187. Highway Safety Institute, Ann Arbor. 